\title{
A Review of Ongoing Trials to Treat COVID-19
}

\author{
Anirban Adhikary ${ }^{1 *}$, Kakoli Halder ${ }^{1}$, Debmalya Ghosh ${ }^{1}$, Snehansu \\ Biswas $^{2}$, Indranil Chatterjee ${ }^{2}$ and Suman Kumar Nath ${ }^{2}$ \\ ${ }^{1}$ B. Pharm, Birbhum Pharmacy School, Birbhum, West Bengal, India \\ ${ }^{2}$ Assistant Professor, Birbhum Pharmacy School, Birbhum, West Bengal, India \\ *Corresponding Author: Anirban Adhikary, B. Pharm, Birbhum Pharmacy School, \\ Birbhum, West Bengal, India.
}

Received: August 27, 2020

Published: October 15, 2020

(C) All rights are reserved by Anirban

Adhikary., et al.

\begin{abstract}
The SARS-CoV-2 infection rose in December 2019 and afterward spread quickly around the world, especially to China, Japan and South Korea. Researchers are attempting to discover antivirals explicit to the infection. Some drugs Such as arbidol, chloroquine, remdesivir and favipiravir are right as of now experiencing clinical evaluations to test their sensibility and security in the treatment of coronavirus disease 2019 (COVID-19) in China, some consoling results have been developed up until now. This article sums up specialists with expected viability against SARS-CoV-2.
\end{abstract}

Keywords: Chloroquine; Pneumonia; COVID-19; SARS-CoV-2; Pandemic; Out Break; Antivirals

\section{Introduction}

The disease SARS-CoV-2 (in the past allotted 2019-nCoV) created in December 2019 and a while later spread rapidly around the globe, particularly to China, Japan and South Korea. From February 21, 2020 onwards an aggregate of 76,288 ensured events of novel coronavirus issue 2019 or (COVID-19) and 2,345 death have been noticed at mainland of China [1]. A part of these authorities have been promptly attempted in clinical examinations and showed groundwork ampleness against COVID-19. Some antivirals such as interferon $\alpha$ (IFN- $\alpha$ ), chloroquine phosphate, lopinavir/ritonavir, chloroquine phosphate, ribavirin and arbidol have been related with most recent kind of Guidelines for Prevention, Diagnosis and treatment for novel Coronavirus-prompted Pneumonia gave by the National Health Commission (NHC) of the People's Republic of China for prohibitive treatment of COVID-19 (Table 1) [2].

\begin{tabular}{|c|c|c|c|}
\hline Drug & Dosage & Method of administration & Duration of treatment \\
\hline IFN- $\alpha$ & 5 million $U$ or equivalent dose each time, 2 times/day & Vapor inhalation & No more than 10 days \\
\hline $\begin{array}{l}\text { Lopinavir/rito- } \\
\text { navir }\end{array}$ & $\begin{array}{c}200 \mathrm{mg} / 50 \mathrm{mg} / \text { capsule, } 2 \text { capsules each time, } 2 \text { times/ } \\
\text { day }\end{array}$ & Oral & No more than 10 days \\
\hline Ribavirin & $\begin{array}{l}500 \mathrm{mg} \text { each time, } 2 \text { to } 3 \text { times/day in combination with } \\
\text { IFN- } \alpha \text { or lopinavir/ritonavir }\end{array}$ & Intravenous infusion & No more than 10 days \\
\hline Arbidol & $200 \mathrm{mg}$ each time, 3 times/day & Oral & No more than 10 days \\
\hline
\end{tabular}

Table 1: Antivirals included in the Guidelines (version 6) for treatment of COVID-19. 
The Guidelines was reevaluated on different events since first being presented on January 15, 2020, the most latest conveyance (the sixth version) was presented on February 18, 2020. The fifth appearance of the Guidelines proposes antivirals including IFN- $\alpha$, lopinavir/ritonavir and ribavirin for treatment of COVID-19 [3]. Chloroquine phosphate and arbidol are remembered for the $6^{\text {th }}$ release of the Guidelines dependent on the fundamental results of clinical investigations [2]. The particular strategy for organization of IFN- $\alpha$ is fume inward breath at a portion of 5 million $U$ (and 2 $\mathrm{mL}$ of sterile water for infusion) for grown-ups, multiple times/ day. The estimation of lopinavir/ritonavir is $400 \mathrm{mg} / 100 \mathrm{mg}$ for adults, on various occasions/day. Ribavirin ought to be managed by means of intravenous mixture at a portion of $500 \mathrm{mg}$ for grownups, 2 to multiple times/day in mix with IFN- $\alpha$ or lopinavir/ritonavir. Chloroquine phosphate is administered orally at a dose of 500 $\mathrm{mg}$ (300 mg for chloroquine) dose for adults is 2 times/day. Arbidol is administered orally at a dose of $200 \mathrm{mg}$ for adults, multiple times/day. The length of treatment is close to 10 days.

IFN- $\alpha$ broad-spectrum antiviral which is generally used for the treatment of hepatitis, though it was reported that it inhibit the SARS-CoV growth in vitro [4]. Lopinavir/ritonavir is used in the treatment of human immunodeficiency virus (HIV) which used in combination with other medications to treat adults and children who are over 14 days of age and are infected by HIV-1 [5]. Chu., et al. noticed that lopinavir/ritonavir has produce an anti-SARS$\mathrm{CoV}$ activity in vitro and in clinical examinations [6]. Ribavirin is a nucleoside simple with a wide range of antiviral impacts. An examination was performed to compare 111 patients having severe acute respiratory syndrome (SARS) which are treated with ribavirin monotherapy and 41 patients having SARS are treated with lopinavir/ritonavir and ribavirin, patients are treated with a combined therapy that has a lower risk of Acute Respiratory Distress Syndrome (ARDS) and causes death. Chloroquine is a generally utilized antimalarial that was seen as a potential wide range antiviral in 2006 [7]. Chloroquine was found to square SARS-CoV-2 pollution at low-micromolar center, with a half-maximal convincing obsession $\left(\mathrm{EC}_{50}\right)$ of $1.13 \mu \mathrm{M}$ and a half-cytotoxic center $\left(\mathrm{CC}_{50}\right)$ more conspicuous than $100 \mu \mathrm{M}$ [8]. Arbidol is an antiviral which can generally be used for the treatment of influenza contamination. An examination has uncovered that arbidol can viably restrain SARSCoV-2 contamination at a centralization of $10-30 \mu \mathrm{M}$ in vitro [9].

Other than the drugs which have included for Guidelines, favipiravir was granted on February 15, 2020 to use in the treatment of novel influenza in China. From February 15, 2020 favipiravir was approved for the treatment of novel flu in China. This medication is at present experiencing facility preliminaries in treating COVID-19. RNA-dependent RNA polymerase (RdRp) inhibitor It was newly found in favipiravir. As it has an anti-flu action for virus, favipiravir shows its ability by obstructing the replication the replication of flavi-, alpha-, filo-, bunya-, arena-, noro- and some other RNA viruses [10]. Favipiravir is changed over into a functioning phosphoribosylated structure (favipiravir-RTP) in cells and is perceived as a substrate by viral RNA polymerase, accordingly restraining RNA polymerase movement [11]. Subsequently, favipiravir may have likely antiviral activity on SARS-CoV-2, which is an RNA infection. A clinical assessment was begun by Clinical Medical Research Center of the National Infectious Diseases and the Third People's Hospital of Shenzhen on February 14 and accomplished some encouraging results on utilizing favipiravir for the therapy of COVID-19. The fundamental outcomes from an aggregate of 80 patients (counting the exploratory gathering and the benchmark group) demonstrated that favipiravir had more strong antiviral activity than that of lopinavir/ritonavir [12]. There was no significant adverse reactions are found at the favipiravir treatment group and it is noticed that there was fewer significantly adverse effects than the lopinavir/ ritonavir group [12]. Remdesivir is another expected medication for treatment of COVID-19. Remdesivir is a nucleoside simple and a wide range antiviral. When the trial was performed on the animals animal [13] it was found that the remdesivir successfully can reduces virals that occupy at mice lung tissue which was infected by MERSCoV, which improve lung function and improve pathological damage to the lung tissue. It was found by Wang., et al. that the remdesivir which can squares SARS-CoV-2 pollution at low micromolar obsessions with a high selectivity record (half-maximal fruitful center $\left(\mathrm{EC}_{50}\right), 0.77 \mu \mathrm{M}$, half-cytotoxic obsession $\left(\mathrm{CC}_{50}\right)>100 \mu \mathrm{M}, \mathrm{SI}$ $>$ 129.87) [8]. Holshue., et al. provided a detailed report where remdesivir yield some hopeful outcomes in the treatment of patients suffering with COVID-19 at the United States [14]. on February 5, 2020 a randomized, placebo-controlled, double-blind, multicenter, phase III clinical examination was held in China In order to examine the efficacy and safety of that drug which is administered into patients having COVID-19. Patients in the exploratory gathering got an underlying portion of $200 \mathrm{mg}$ of remdesivir and a resulting portion of 100 mg for 9 back to back days by means of intravenous mixture notwithstanding routine treatment. Patients in the benchmark group got standard treatment and a similar portion of a fake treatment. The preliminary is relied upon to finish up before the finish of April 2020. 
Studies have additionally uncovered some different medications may have expected adequacy in treating COVID-19. Darunavir which is a second-age if there should be an occurrence of HIV-1 protease inhibitor. At china the researchers on February 4, 2020 declared that darunavir can be inhibited for SARS-CoV-2 infection in vitro [9]. Cell tests showed that darunavir fundamentally restrained viral replication at a centralization of $300 \mu \mathrm{M}$ in vitro and that its hindrance productivity was 280 -overlay that in the untreated gathering [9]. Some possible medications Type II transmembrane serine protease (TMSPSS2) inhibitors and BCR-ABL kinase inhibitor imatinib. Hoffmann., et al. mentioned that SARS$\mathrm{CoV}$ receptor, ACE2 and the cellular protease TMPRSS2 was used by SARS-CoV-2 to attack into the targeted cells. A TMPRSS2 inhibitor would square passage and in this way comprise a treatment choice [17]. It is noticed that imatinib inhibits the fusion of virions with the endosomal membrane which refer give it an anti-coronal action [18].

A joint examination bunch from Shanghai Institute of Materia Medica and Shanghai Tech University at January 25, 2020 held a medication screening in silicon and a catalyst movement test and they found that 30 casualties indicating expected antiviral action against SARS-CoV-2 [19]. Indinavir, saquinavir, lopinavir, carfilzomib, ritonavir, remdesivir, atazanavir, darunavir, tipranavir, fosamprenavir, elvitegravir, maribavir, raltegravir, montelukast, deoxyrhapontin, enzaplatovir, presatovir, abacavir, bortezomib, polydatin, chalcone, disulfiram, carmofur, shikonin, ebselen, tideglusib, PX12, TDZD-8, cyclosporine-A and cinanserin are the Casualties. In Chinese natural prescriptions likr Rhizoma Polygoni Cuspidati and Radix Sophorae Tonkinensis was discovered that they contain some dynamic fixings that neutralize SARS-COV-2 when a comparable assessment was [19].

\section{Conclusion}

Similar examination was held and it was noticed As the plague spreads, researchers around the globe are effectively investigating drugs that would be possibly successful in fighting COVID-19. By and large, there are no at last checked antivirals explicit to COVID-19 at present. Further preclinical and clinical trials should held for the drugs which are use in the treatment of COVID-19 to confirm their efficacy and safety.

\section{Declaration of Competing Interest}

The author declares that there is no competing interest in this work.

\section{Bibliography}

1. Update on the prevalence and control of novel coronavirusinduced pneumonia as of 24:00 on February 21 (2020).

2. Guidelines for the Prevention, Diagnosis, and Treatment of Novel Coronavirus-induced Pneumonia, The $6^{\text {th }}$ edition (2020).

3. Guidelines for the Prevention, Diagnosis, and Treatment of Novel Coronavirus-induced Pneumonia, The $5^{\text {th }}$ edition (2020).

4. Stockman LJ., et al. "SARS: Systematic review of treatment effects”. PLOS Medicine 3 (2006): e343.

5. Su B., et al. "Efficacy and tolerability of lopinavir/ritonavirand efavirenz-based initial antiretroviral therapy in HIV-1infected patients in a tertiary care hospital in Beijing, China". Frontiers in Pharmacology 10 (2019): 1472.

6. Chu CM., et al. "Role of lopinavir/ritonavir in the treatment of SARS: Initial virological and clinical findings". Thorax 59 (2004): 252-256.

7. Savarino A., et al. "New insights into the antiviral effects of chloroquine". The Lancet Infectious Diseases 6 (2006): 67-69.

8. Wang M., et al. "Remdesivir and chloroquine effectively inhibit the recently emerged novel coronavirus (2019-nCoV) In vitro". Cell Research (2020).

9. News: Abidol and darunavir can effectively inhibit coronavirus (2020).

10. Delang L., et al. "Favipiravir as a potential countermeasure against neglected and emerging RNA viruses". Antiviral Research 153 (2018): 85-94.

11. Furuta Y., et al. "Favipiravir (T-705), a broad spectrum inhibitor of viral RNA polymerase". Proceedings of the Japan Academy, Series B, Physical and Biological Sciences 93 (2017): 449463.

12. News. http://www.szdsyy.com/News/0a6c1e58-e3d0-4cd1867a-d5524bc59cd6.html (2020).

13. Sheahan TP., et al. "Comparative therapeutic efficacy of remdesivir and combination lopinavir, ritonavir, and interferon beta against MERS-CoV". Nature Communications 11 (2020): 222.

14. Holshue ML., et al. "First case of 2019 novel coronavirus in the United States". The New England Journal of Medicine (2020).

15. Mild/Moderate 2019-nCoV Remdesivir RCT (2020). 
16. Severe 2019-nCoV Remdesivir RCT (2020).

17. Hoffmann M., et al. "The novel coronavirus 2019 (2019-nCoV) uses the SARS-coronavirus receptor ACE2 and the cellular protease TMPRSS2 for entry into target cells". Bio Rxiv (2020).

18. Coleman CM., et al. "Abelson kinase inhibitors are potent inhibitors of severe acute respiratory syndrome coronavirus and Middle East respiratory syndrome coronavirus fusion". Journal of Virology 90 (2016): 8924-8933.

19. Shanghai Institute of Materia Medica website, Chinese Academy of Sciences. A joint research team of the Shanghai Institute of Materia Medica and Shanghai Tech University discover a group of old and traditional Chinese medicines that may be efficacious in treating the novel form of pneumonia (2020).

\section{Assets from publication with us}

- Prompt Acknowledgement after receiving the article

- Thorough Double blinded peer review

- Rapid Publication

- Issue of Publication Certificate

- High visibility of your Published work

Website: https://www.actascientific.com/

Submit Article: https://www.actascientific.com/submission.php

Email us: editor@actascientific.com

Contact us: +919182824667 